\title{
Gross motor coordination in relation to weight status in 7- to 9-year-old children
}

\author{
Ingrid Ružbarská* \\ Faculty of Education, University of Presov, Presov, Slovakia
}

Copyright: (C) 2020 I. Ružbarská. This is an open access article licensed under the Creative Commons Attribution License (https://creativecommons.org/licenses/by/4.0/).

\begin{abstract}
Background: The prevalence of childhood obesity is increasing worldwide with its negative health and psychosocial consequences. Research evidence suggests that obesity is strongly associated with low motor competence. In the past two decades, there has been increasing evidence that motor competence is crucial for developing an active and healthy lifestyle. Objective: The purpose of the study was to investigate gross motor coordination in overweight and obese children compared with normal-weight peers. Methods: Data were collected in 326 children (160 boys, 49.1\%) aged 7-9 years (mean 8.02, SD 0.81). Their weight status determined by body mass index (BMI) was defined in accordance with the International Obesity Task Force cut-off points for children and they were classified into two BMI groups: a normal-weight group and an overweight/obese group. Gross motor coordination was identified by means of the Körperkoordination Test für Kinder (KTK). Differences between groups were evaluated using independent samples $t$-test. Pearson correlations were performed to explore the associations between motor coordination indicators and BMI. Results: This study demonstrated that gross motor coordination is significantly lower in overweight and obese girls and boys than in normal-weight children. Small to moderate inverse correlations $(-.18 \leq r \leq-.39)$ were found between KTK parameters and BMI, for both sexes. More than $15 \%$ of the normal-weight children were identified as being motor impaired, but that proportion was $59.3 \%$ in overweight and obese children. Conclusions: Children with normal weight of both sexes demonstrated significantly higher gross motor coordination than overweight and obese children. Considering the crucial role of motor competence in physical activity engagement, there is a need for early identification of possible motor impairments in overweight or obese children.
\end{abstract}

Keywords: childhood, motor competence, obesity, physical activity

\section{Introduction}

The prevalence of childhood obesity is increasing worldwide both in developed and developing countries. This increase is alarming as the health risks caused by obesity, together with psychosocial consequences for the individual, are no longer just a phenomenon typical of the adult population (Henriksson et al., 2016; $\mathrm{Ng}$ et al., 2014; Wang \& Lobstein, 2006). A longitudinal study showed a risk that obese children will become obese adults who are consequently exposed to increased risk of comorbidity and premature mortality (Herman, Craig, Gauvin, \& Katzmarzyk, 2009). Obviously, in addition to genetic predispositions and inappropriate dietary composition, the lack of physical activity and a sedentary lifestyle significantly

\footnotetext{
* Address for correspondence: Ingrid Ružbarská, Department of Music, Art, and Physical Education, Faculty of Education, University of Presov, ul. 17. novembra 15, 08116 Presov, Slovakia.E-mail: ingrid.ruzbarska@unipo.sk
}

contribute to children's obesity (Katzmarzyk, Janssen, \& Ardern, 2003).

Ahrens et al. (2014) report that $19.8 \%$ of children (2-10 years) were overweight or obese on a European scale, of which $7 \%$ were obese. Slightly higher rates of overweight or obesity are confirmed in girls $(21.1 \%)$ compared to boys (18.6\%). Ng et al. (2014) state that, in 2013, the incidence of overweight or obesity in the population of boys under 20 years was $23.8 \%$ and $22.6 \%$ in girls worldwide.

Motor competence is considered a crucial component in developing a healthy and active lifestyle from early childhood (Cattuzzo et al., 2016; Coppens et al., 2019; Robinson et al., 2015). Stodden et al. (2008) proposed a conceptual model in which developmentally reciprocal relationships among motor competence, physical activity, and risk for obesity are described. The model hypothesizes motor competence and physical activity synergistically influence children's weight status either positively or negatively. Within the model, 
a negative spiral of disengagement explains how lower levels of motor competence and physical activity are associated with a higher risk of obesity (De Meester et al., 2016). Moreover, health-related fitness and perceived motor competence were proposed as important mediating factors in the model (Robinson et al., 2015). As stated by Stodden et al. (2008) and Robinson et al. (2015), the model suggests that the development of motor competence initially promotes health-related fitness in early childhood and, in middle and late childhood, fitness mediates the relationship between physical activity and motor competence as increased health-related fitness positively affects a child's ability to persist in physical activities for longer periods. Furthermore, perceived motor competence mediates the relationship between physical activity and actual motor competence. This relationship is suggested to strengthen with increasing age because of the strong mediating influence of individuals' perceptions of their motor skill performance, which becomes more accurate as children get older (Barnett, Morgan, van Beurden, \& Beard, 2008).

There has been an increasing interest in studying associations between gross motor coordination and physical parameters in early childhood over the past decade (D'Hondt et al., 2013). Evidence from several research studies indicates an inverse association between gross motor coordination and weight status in childhood (D’Hondt, Deforche, De Bourdeaudhuij, \& Lenoir, 2009; D’Hondt et al., 2010; Graf et al., 2004; Lopes, Stodden, Bianchi, Maia, \& Rodrigues, 2012; Okely, Booth, \& Chey, 2004). Regardless of motor diagnostic tool and methodological approach, lower fundamental skills and motor coordination parameters have been consistently reported in overweight and obese children as compared to their healthy-weight peers (D'Hondt et al., 2014). It has been shown that obese children also suffer from impaired fine motor skills even though in these tasks the outcome is mostly determined by the quality of information processing or the integration of sensory information (Gentier et al., 2013). Robinson et al. (2015) assume that motor coordination is both a precursor and a consequence of weight status in childhood.

However, furthermore, research is needed to gain a better insight into the mechanisms underlying motor competence associated with childhood obesity and to define objectives to promote health-oriented physical fitness and regular physical activity within this population (D'Hondt et al., 2013).

An increased focus on the learning of motor skills aimed at lifelong physical activity is considered to be crucial during primary school age when children are at an optimal developmental period in terms of neurological and motor development (D'Hondt et al., 2013). Developing an adequate level of motor competence provides a protective effect against decreasing physical activity and excessive body weight across childhood (Robinson et al., 2015). As stated by D'Hondt et al. (2013) and Lopes et al. (2012), research results underline the need to target overweight and obese children for an early screening of motor coordination and associated intervention.

It is important to understand the impact of excessive body weight on motor functions during childhood in order to provide effective strategies for motor development of children (D'Hondt et al., 2010). Thus, considering a high prevalence of overweight and obesity in primary school children and the crucial role of motor competence in physical activity engagement, the main purpose of this study was to investigate gross motor coordination in overweight and obese primary schoolaged children compared with normal-weight peers. We also examined the association between motor coordination indicators and weight status in primary schoolaged children.

\section{Methods}

\section{Participants}

A total of 11 primary schools were randomly selected from the schools in the region of East Slovakia. Among them, 7 schools (18 classes) agreed to participate in the study. A sample of 326 children (160 boys, 49.1\%) with a mean age of 8.02 years $(S D=0.81$; range 7-9 years) finally participated in this study with a cross-sectional design. The research sample included only the individuals without health limitations that could affect their performance on motor coordination tests. Their participation was voluntary. For each participant, written informed consent was obtained from the parents or guardians. The Ethics Committee of the University of Presov in Presov (Slovakia) approved the study. All procedures were conducted in agreement with the principles expressed in the Declaration of Helsinki.

\section{Data collection}

Assessments of anthropometry and children's gross motor coordination took place in the gymnasiums of the schools during regular physical education classes. All testing was conducted by a group of trained examiners using standardized instructions.

Body height was measured barefoot to the nearest $0.1 \mathrm{~cm}$ using a portable stadiometer (Harpenden, Holtain, Crymych, United Kingdom). Body weight was measured in minimal clothing to the nearest $0.5 \mathrm{~kg}$ using a digital scale (Omron HN-286, Omron, Kyoto, Japan). 
Body mass index (BMI) was calculated to determine children's weight status by dividing body mass (in $\mathrm{kg}$ ) by height squared (in $\mathrm{m}$ ). According to the international cut-off points for BMI in children provided by Cole, Belizzi, Flegal, and Dietz (2000), participants were classified into two BMI groups: a normal-weight group and an overweight/obese group. For girls, the cut-off values for distinguishing between the mentioned two groups were: $18.03 \mathrm{~kg} / \mathrm{m}^{2}$ (7.5 years), 18.69 $\mathrm{kg} / \mathrm{m}^{2}(8.5$ years $)$ and $19.45 \mathrm{~kg} / \mathrm{m}^{2}$ (9.5 years). The BMI cut-off points applied for boys were as follows: 18.16 $\mathrm{kg} / \mathrm{m}^{2}$ (7.5 years), $18.76 \mathrm{~kg} / \mathrm{m}^{2}$ (8.5 years) and 19.46 $\mathrm{kg} / \mathrm{m}^{2}$ (9.5 years).

Five skinfolds (triceps, biceps, subscapular, supraspinal, medial calf) were measured on the right side of the body to the nearest $0.1 \mathrm{~mm}$, following the protocol described by Adam, Klissouras, Ravazollo, Renson, and Tuxworth (1988). A Holtain skinfold calliper (Holtain, Crymych, United Kingdom) was used. Additionally, the sum of the measured skinfolds was calculated to provide an estimate of subcutaneous fat.

The Körperkoordination Test für Kinder (KTK; Kiphard \& Schilling, 1974, 2007) was used to evaluate gross motor coordination. It is a standardized normative product-oriented test battery for 5- to 14-year-old children with typical and atypical motor development. The test battery includes four subtests:

1. Balancing backwards: walking backwards along balance beams of decreasing width: $6 \mathrm{~cm}, 4.5 \mathrm{~cm}$, and $3 \mathrm{~cm}$,

2. Hopping one leg: one-legged hopping over a foam squares ( $50 \mathrm{~cm}$ long $\times 20 \mathrm{~cm}$ wide $\times 5 \mathrm{~cm}$ high) with increasing height in consecutive steps of $5 \mathrm{~cm}$,

3. Jumping laterally: two-legged jumping from side to side over a wooden bar $(60 \mathrm{~cm}$ long $\times 4 \mathrm{~cm}$ wide $\times 2$ $\mathrm{cm}$ high) in $15 \mathrm{~s}$,

4. Moving sideways: moving sideways on wooden platforms $(25 \mathrm{~cm} \times 25 \mathrm{~cm} \times 5 \mathrm{~cm})$ in $20 \mathrm{~s}$.

The raw scores of each test items were converted into standardised scores, adjusted for age and sex, using normative data tables in the KTK manual. The sum of standardised scores for each test provides the motor quotient (MQ). The KTK MQ adjusted for age and gender allows for the assessment of total gross motor coordination in the following categories: a severe motor disorder of gross motor coordination (MQ 56-70, percentile $0-2$ ), a moderate motor disorder of gross motor coordination (MQ 71-85, percentile 3-15), normal gross motor coordination (MQ 86-115, percentile 16-84), good gross motor coordination (MQ 116-130, percentile 85-98), and high gross motor coordination (MQ 131-145, percentile 99-100; Kiphard \& Schilling, 1974, 2007). Reported reliability coefficients for the KTK ranged from .80 to .96 for individual test items. The reliability coefficient was .97 for the total battery. The percentage of total variance in motor coordination explained by all test items varied from $81 \%$ at the age of six years to $98 \%$ at the age of nine years.

\section{Statistical analysis}

Observed data were processed using the IBM SPSS Statistics (Version 20.0; IBM, Armonk, NY, USA). The normality test by Shapiro Wilk was used to verify normality of the data distribution. Levene's test was also used to assess the equality of variances. Descriptive statistics (mean $\pm S D$ ) was calculated for both anthropometric and motor variables. An independent samples $t$-test was applied to compare both anthropometric and motor characteristics between normal-weight and overweight/obese groups. Pearson correlation coefficients were also calculated to examine mutual relations between BMI and KTK parameters. The level of statistical significance was set at $\alpha=.05$. Effect size was evaluated by Cohen's $d$. The values of $d=0.2, d=0.5$ and $d=0.8$ were interpreted as small, medium and large effects, respectively (Cohen, 1988, 1992).

\section{Results}

Based on the cut-off points for BMI (Cole et al., 2000), a classification into two BMI-groups was applied: normal-weight (81.9\% of participants), and overweight or obese (18.1\% of participants). For both boys and girls, the percentage of obese individuals equalled approximately $6 \%$. Out of the 326 participants, $78.3 \%$ of girls and $85.6 \%$ of boys were classified as normal-weight, and $21.7 \%$ and $14.4 \%$ as overweight or obese, respectively.

In accordance with that classification, detailed anthropometric characteristics are presented in Table 1. Overweight/obese girls and boys showed significantly higher skinfold thickness than normal-weight children as indicated by practical significance with large effect sizes (girls and boys: $d=1.11$, girls: $d=1.04$, boys: $d=1.16)$. The results also show a tendency for overweight or obese children to be taller compared with normal-weight children $(t(158)=5.70, \quad p<.001)$. However, this tendency was not confirmed for girls $(t(164)=1.17, p=.243)$.

The main results regarding KTK scores are shown in Table 2. Independent samples $t$-test revealed statistically significant differences between normal-weight children and their overweight and obese counterparts in all examined motor coordination subtests. Normalweight children had also significantly higher total KTK score (MQ) than overweight and obese children as indicated by practical significance with large effect size 
Table 1

Age and anthropometric characteristics $(M \pm S D)$ according to the level of body mass index

\begin{tabular}{lcc}
\hline Characteristic & Normal-weight & Overweight/Obese \\
\hline Age (years) & & \\
Girls and boys & $7.99 \pm 0.82$ & $8.10 \pm 0.78$ \\
Girls & $8.02 \pm 0.82$ & $7.94 \pm 0.83$ \\
Boys & $7.97 \pm 0.82$ & $8.35 \pm 0.65$ \\
Body weight (kg) & & \\
Girls and boys & $25.96 \pm 4.18$ & $38.27 \pm 6.95$ \\
Girls & $25.77 \pm 3.98$ & $35.49 \pm 5.53$ \\
Boys & $26.15 \pm 4.36$ & $42.63 \pm 6.78$ \\
Body height (cm) & & \\
Girls and boys & $129.66 \pm 7.98$ & $134.76 \pm 8.79$ \\
Girls & $129.77 \pm 8.05$ & $131.53 \pm 7.58$ \\
Boys & $129.56 \pm 7.94$ & $139.83 \pm 8.26$ \\
Sum of 5 skinfolds (mm) & \\
Girls and boys & $40.04 \pm 8.48$ & $51.44 \pm 12.56$ \\
Girls & $41.73 \pm 8.08$ & $51.92 \pm 11.34$ \\
Boys & $38.73 \pm 8.56$ & $50.70 \pm 14.50$ \\
\hline
\end{tabular}

Note. There were 267 children in the normal-weight group (130 girls, 137 boys) and 59 children in the overweight/obese group (36 girls, 23 boys) $(t(324)=5.94, p<.001, d=0.81)$. In the group of overweight and obese children, the mean value of the MQ (85.23) reached the upper limit of moderate motor disorder (MQ $\leq 85)$, with the normal-weight children it was just about in the normal range (see Table 2). In fact, in the group of overweight/obese children ( $n=59), 3$ individuals (1 girl and 2 boys) reached the upper limit (MQ $\leq 85$ ) for moderate motor coordination disorder.

Independent samples $t$-test showed that overweight and obese girls displayed significantly lower scores in dynamic balance (Balancing backwards), speed of locomotor coordination (Moving sideways) and in the parameter of total motor proficiency $(\mathrm{MQ}: t(164)=2.7$, $p=.010$ ) than their non-obese peers (see Table 2). For boys, there were statistically significant differences between the BMI-groups in all examined coordination parameters with the exception of Jumping laterally. In both girls and boys, there were no statistically significant differences in the weight-bearing task (Jumping laterally) between the BMI-groups. Moreover, no significant difference was found between hopping for height performances of overweight/obese and normalweight girls $(t(164)=1.41, p=.161)$. Nevertheless, results indicate that BMI-related differences in gross

Table 2

Comparison of coordination indicators according to the level of body mass index

\begin{tabular}{|c|c|c|c|c|c|}
\hline Indicator & $\begin{array}{l}\text { Normal-weight } \\
\qquad(M \pm S D)\end{array}$ & $\begin{array}{l}\text { Overweight/Obese } \\
\qquad(M \pm S D)\end{array}$ & $t$ & $p$ & Cohen's $d$ \\
\hline \multicolumn{6}{|c|}{ Balancing backwards (steps) } \\
\hline Girls and boys & $43.59 \pm 14.21$ & $34.29 \pm 14.56$ & 4.53 & $<.001$ & 0.63 \\
\hline Girls & $45.48 \pm 13.43$ & $37.36 \pm 14.08$ & 3.18 & .002 & 0.55 \\
\hline Boys & $41.80 \pm 14.75$ & $29.48 \pm 14.26$ & 3.72 & $<.001$ & 0.84 \\
\hline \multicolumn{6}{|c|}{ Hopping one leg (points) } \\
\hline Girls and boys & $46.53 \pm 16.03$ & $39.68 \pm 15.82$ & 2.98 & .003 & 0.43 \\
\hline Girls & $43.77 \pm 15.75$ & $39.64 \pm 14.93$ & 1.41 & .161 & 0.26 \\
\hline Boys & $49.15 \pm 15.90$ & $39.74 \pm 17.46$ & 2.59 & .011 & 0.58 \\
\hline \multicolumn{6}{|c|}{ Jumping laterally (jumps) } \\
\hline Girls and boys & $45.23 \pm 13.25$ & $41.29 \pm 14.54$ & 2.03 & .043 & 0.29 \\
\hline Girls & $45.87 \pm 13.88$ & $41.50 \pm 16.17$ & 1.61 & .109 & 0.32 \\
\hline Boys & $44.61 \pm 12.66$ & $40.96 \pm 11.88$ & 1.29 & .198 & 0.26 \\
\hline \multicolumn{6}{|c|}{ Moving sideways (transfers) } \\
\hline Girls and boys & $37.67 \pm 7.65$ & $34.24 \pm 8.41$ & 3.07 & .002 & 0.44 \\
\hline Girls & $37.65 \pm 8.14$ & $34.28 \pm 9.45$ & 2.12 & .036 & 0.43 \\
\hline Boys & $37.70 \pm 7.18$ & $34.17 \pm 6.66$ & 2.20 & .029 & 0.45 \\
\hline \multicolumn{6}{|c|}{ Motor quotient (standardized score) } \\
\hline Girls and boys & $96.65 \pm 12.88$ & $85.23 \pm 15.40$ & 5.94 & $<.001$ & 0.81 \\
\hline Girls & $94.66 \pm 12.28$ & $86.83 \pm 16.14$ & 2.70 & .010 & 0.56 \\
\hline Boys & $98.53 \pm 13.18$ & $82.74 \pm 14.14$ & 5.26 & $<.001$ & 1.12 \\
\hline
\end{tabular}

Note. There were 267 children in the normal-weight group (130 girls, 137 boys) and 59 children in the overweight/obese group (36 girls, 23 boys). 
motor coordination were slightly more pronounced for boys. According to normative values of KTK test battery (Kiphard \& Schilling, 1974, 2007), results for overweight/obese girls were at the lower ranges of "normal gross coordination" (MQ = 86.32). Nevertheless, for overweight/obese boys the results were indicative of "moderate motor disorder" (MQ = 82.74).

Correlations among gross motor coordination indicators and BMI are presented in Table 3. In general, significant small to moderate inverse correlations between BMI and motor test results of the children were found for the whole group as well as separately for boys and girls $(-.18 \leq r \leq-.39)$. Of the all KTK parameters measured, the MQ was found to have the strongest adverse relationship with BMI for all subgroups $(-.26 \leq$ to $\leq-.39, p<.01)$. Weight-bearing task (Jumping laterally) was found not to have a

Table 3

Pearson correlations (r) between body mass index and the indicators of the KTK test

\begin{tabular}{lcll}
\hline & \multicolumn{3}{c}{ Body mass index } \\
\cline { 2 - 4 } Indicator & Girls & & \\
\hline and boys & Girls & Boys \\
\hline Balancing backwards & $-.23 * *$ & $-.18^{*}$ & $-.28^{* *}$ \\
Hopping one leg & $-.20 * *$ & -.15 & $-.25 * *$ \\
Jumping laterally & -.10 & -.08 & -.12 \\
Moving sideways & $-.20 * *$ & -.14 & $-.26 * *$ \\
Motor quotient & $-.32 * *$ & $-.26 * *$ & $-.39 * *$ \\
\hline
\end{tabular}

Note. $* p<.05, * * p<.01$. significant relationship with BMI. Moreover, motor indicators were more often correlated with BMI in boys than girls.

From the diagnostic point of view, it was worthwhile to have a closer look at the percentage of children within each BMI-group scoring on the MQ. As shown in Figure 1, of the group of normal-weight children ( $n=267), 15.4 \%$ were found to have MQ $\leq 85$. Out of the normal-weight children, $18.5 \%$ of girls and $12.4 \%$ of boys were considered to have moderate or severe disorder of gross motor coordination. A significantly different tendency was observed in the group of overweight or obese children of whom $59.3 \%$ showed a motor quotient below the normal level of gross motor coordination $(\mathrm{MQ} \leq 85)$. Of the entire group of overweight and obese children, $55.6 \%$ of girls and $65.2 \%$ of boys scored below the normal coordination level (MQ $\leq 85)$. These findings point to the higher prevalence of motor deficits in overweight and obese children compared with normal-weight girls and boys.

\section{Discussion}

The main purpose of this study was to investigate gross motor coordination in overweight and obese primary school-aged children compared with normalweight peers. In line with previous research (D'Hondt et al., 2009; D'Hondt et al., 2010; Lopes et al., 2012; Lubans, Morgan, Cliff, Barnett, \& Okely, 2010; Ružbarská, 2016), our results indicated that normalweight children significantly outperformed overweight

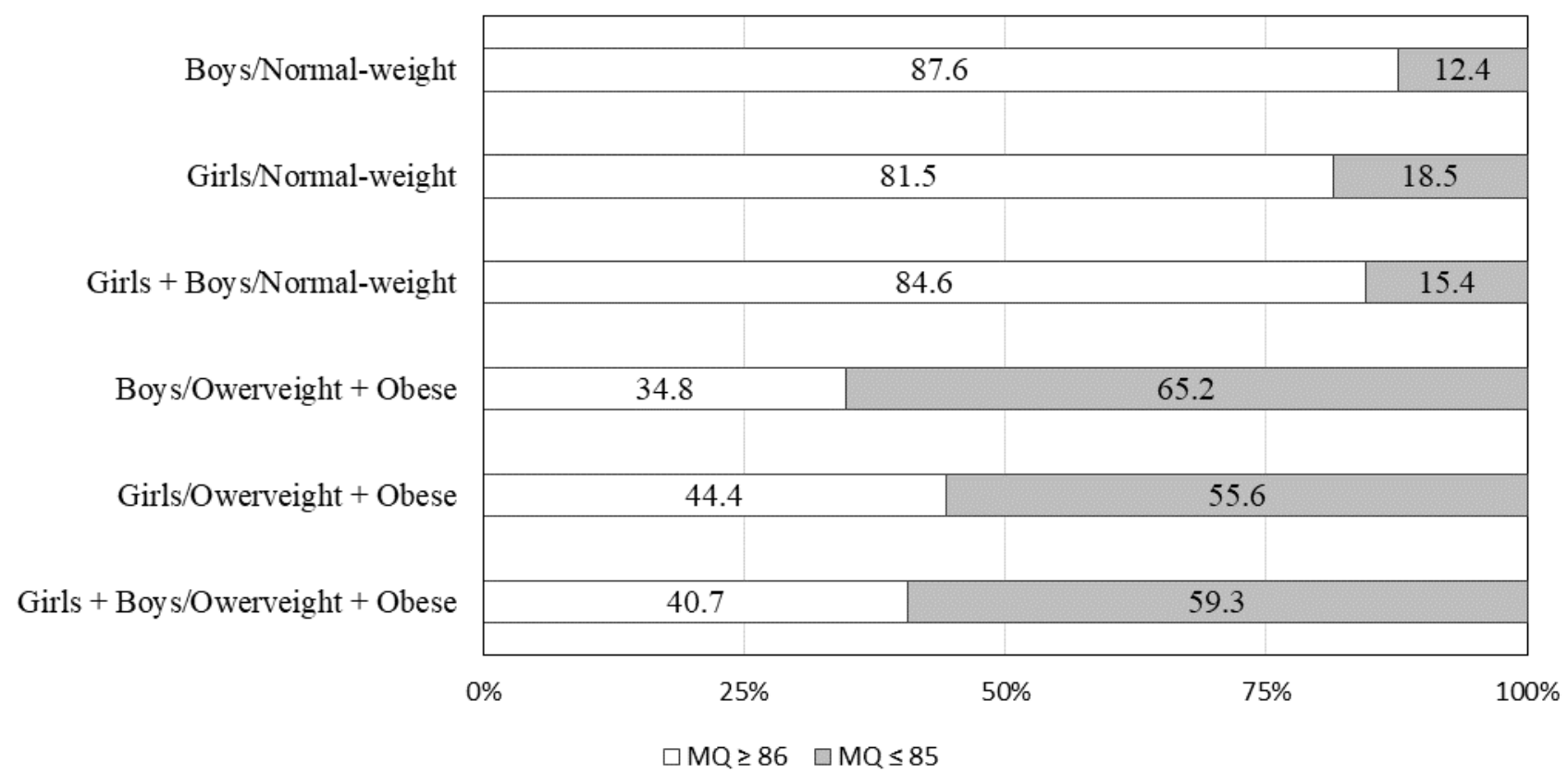

Figure 1. Distribution of the KTK motor quotient (MQ) in the groups divided by body mass index. 
and obese children on all subtests of the KTK test. The results demonstrated that childhood obesity is associated with total lower gross motor coordination. Indeed, weight status had a significant negative impact on gross motor coordination.

Lopes et al. (2012) conducted a cross-sectional study on a sample of 7175 children aged 6-14 years demonstrating that gross motor coordination (KTK) is negatively correlated with BMI. Correlations between motor coordination parameters and BMI were negative and varied between -.20 to -.29 in children from 7 to 9 years of age. Likewise, small to moderate significant correlations $(-.18 \leq \mathrm{r} \leq-.39)$ were found between the majority of the KTK parameters and BMI, for both sexes from our sample.

The inverse relationship between gross motor coordination and body weight is frequently explained from a mechanical point of view because excessive body weight affects body geometry and increases the mass of individual body segments. Nevertheless, it is believed that the reported inverse relationship between motor coordination and BMI is mediated by several alternative mechanisms (D’Hondt et al., 2009). As noticed by D'Hondt et al. (2009), a lower socioeconomic status could be associated with obesity and lower levels of motor skill performance. Furthermore, research has demonstrated more obesity in a group of children with Developmental Coordination Disorder (Cairney, Hay, Faught, \& Hawes, 2005). Another explanation could be that obese children avoid weight-bearing tasks because of the greater energy demands in comparison with normal-weight children. Thus, the poorer performance of obese individuals might be also a consequence of a lack of experience in weight-bearing activities (Bar-Or, 1993).

As stated by Malina, Bouchard, and Bar-Or (2004) overweight and obesity has a negative effect on tasks where the body is moved or projected through space, or the lifting and supporting of the body off the ground. It can be suggested that obese children perform worse mostly in weight-bearing tasks because a greater proportion of excess mass has to be supported (D'Hondt et al., 2009; Gentier et al., 2013). By contrast, there were no statistically significant differences in weight-bearing tasks between the BMI-groups for both girls and boys from our research sample (Jumping laterally). Likewise, among 6-year-old children, performances on jumping laterally did not differ among weight status groups of boys (Lopes, Malina, Maia, \& Rodrigues, 2018).

Several studies showed more limited motor competence among obese boys compared to normal-weight peers, but these results were not confirmed in girls (Castetbon \& Andreyeva, 2012; Cawley \& Spiess, 2008). Similarly, our findings indicate that differences between normal-weight and overweight/obese children were slightly more pronounced for boys than for girls.

The results of this study also correspond to the current knowledge of the prevalence of overweight and obesity in primary school-aged children. Scientific studies, in which the BMI International Obesity Task Force standards were used, suggest that around $20 \%$ of school-aged children (5-17 years) in European countries are overweight or obese. The proportion of obese children is approximately $3 \%$ in boys and nearly 5\% in girls (Lobstein, Baur, \& Uauy, 2004). As reported by D'Hondt et al. (2010), less than $20 \%$ of the healthy-weight children were identified as being motor impaired, while that proportion was $43 \%$ and $70.8 \%$ in overweight and obese children, respectively. A similar tendency was observed in our study. More than 15\% of the normal-weight children were identified as being motor impaired, but that proportion was $59.3 \%$ in overweight and obese children.

It has been confirmed that obese children display lower fitness levels and motor competencies (Graf et al., 2004). Overweight or obese children are less fit and are more likely to experience less positive experiences and success when performing physical activities. Consequently, their motivation, participation and preferences related to physical activity will reduce, which may naturally lead to a decline in fitness, motor competences and formation of a sedentary and less active lifestyle (Stodden et al., 2008; Wrotniak, Epstein, Dorn, Jones, \& Kondilis, 2006).

According to systematic reviews (Barnett et al., 2016; Lubans et al., 2010), children of all ages who are less motor competent are less physically active, which may increase unhealthy weight gain. In addition, longitudinal evidence indicates that being skilled as a child is associated with being more physically active in late childhood and adolescence (Barnett et al., 2016). It is shown that active leisure behaviour is accompanied by better results of gross motor development, whereas sedentary habits correlate slightly with poorer gross motor development. These findings underline the importance of an active lifestyle to prevent overweight or obesity in early childhood (Graf et al., 2004).

Gross motor coordination can be considered as a proxy health indicator of children (Henrique et al., 2017). The development of motor competence during childhood is decisive for a healthy lifestyle, since it will allow individuals to successfully participate in a variety of leisure or sport activities across the lifespan (Barnett, Morgan, van Beurden, Ball, \& Lubans, 2011; Barnett, van Beurden, Morgan, Brooks, \& Beard, 2009; Lopes, Stodden, \& Rodrigues, 2017; Stodden et al., 2008).

Several limitations of the study should be mentioned. Firstly, due to the cross-sectional design, no causality 
can be defined from the research data. Another limiting factor of our research approach is the application of BMI itself. BMI is a suboptimal marker of body fat because it does not differentiate fat from lean tissue or bone. However, Cole's international BMI cut-offs provide a reasonable measure of adiposity for monitoring weight at the population level (Cole et al., 2000).

Given the role of gross motor coordination in the development of an active and healthy lifestyle, longitudinal research is needed to explore individual changes in gross motor coordination across childhood and develop more effective movement programs for children. Future studies should also include other determinants that may affect motor proficiency, such as the level of physical activity, perceived motor competence, and socioeconomic status (D’Hondt et al., 2010).

\section{Conclusions}

The present study showed significantly worse results of overweight/obese children than normal-weight children with regard to gross motor coordination. Moreover, the present findings point to the higher prevalence of motor impairments in children with overweight and obesity. The study reinforces the idea that excessive body weight provides a constraint for gross motor coordination in primary school children. On the contrary, performances on weight-bearing task (Jumping laterally) did not differ significantly between weight status groups of girls and boys.

\section{Acknowledgments}

The paper was supported by the scientific project No. 1/0122/19 "Somatic and motor characteristics of primary school children and their development trends with the focus on marginalized Romany communities", which was funded by the Scientific Grant Agency of the Ministry of Education, Science, Research and Sports of the Slovak Republic and Slovak Academy of Sciences.

\section{Conflict of interest}

There were no conflicts of interest.

\section{References}

Adam, C. V., Klissouras, M., Ravazollo, R., Renson, W., \& Tuxworth, W. (1988). Eurofit. Handbook for the European test of physical fitness. Rome, Italy: Council of Europe, Committee for Development of Sport.

Ahrens, W. I., Pigeot, I., Pohlabeln, H., De Henauw, S., Lissner, L., Molnár, D., ... Siani, A. (2014). Prevalence of overweight and obesity in European children below the age of 10. International Journal of Obesity, 38(Suppl. 2), S99-S107.

Bar-Or, O. (1993). Physical activity and physical training in childhood obesity. Journal of Sports Medicine and Physical Fitness, 33, 323-329.

Barnett, L. M., Lai, S. K., Veldman, S. L. C., Hardy, L. L., Dylan, P. C., Philip, J., ... Okely, A. D. (2016). Correlates of gross motor competence in children and adolescents: A systematic review and meta-analysis. Sports Medicine, 46, 1663-1688.

Barnett, L. M., Morgan, P. J., van Beurden, E., Ball, K., \& Lubans, D. R. (2011). A reverse pathway? Actual and perceived skill proficiency and physical activity. Medicine \& Science in Sports \& Exercise, 43, 898-904.

Barnett, L. M., Morgan, P. J., van Beurden, E., \& Beard, J. R. (2008). Perceived sports competence mediates the relationship between childhood motor skill proficiency and adolescent physical activity and fitness: A longitudinal assessment. International Journal of Behavioral Nutrition and Physical Activity, 5, 40.

Barnett, L. M., van Beurden, E., Morgan, P. J., Brooks, L. O., \& Beard, J. R. (2009). Childhood motor skill proficiency as a predictor of adolescent physical activity. Journal of Adolescent Health, 44, 252-259.

Cairney, J., Hay, J. A., Faught, B. E., \& Hawes, R. (2005). Developmental coordination disorder and overweight and obesity in children aged 9-14 y. International Journal of Obesity, 29, 369-372.

Castetbon, K., \& Andreyeva, T. (2012). Obesity and motor skills among 4 to 6-year-old children in the United States: Nationally-representative surveys. BMC Pediatrics, 12, 28.

Cattuzzo, M. T., Dos Santos Henrique, R., Ré, A. H., de Oliveira, I. S., Melo, B. M., de Sousa Moura, M., ... Stodden, D. (2016). Motor competence and health related physical fitness in youth: A systematic review. Journal of Science and Medicine in Sport, 19, 123-129.

Cawley, J., \& Spiess, C. K. (2008). Obesity and skill attainment in early childhood. Economics \& Human Biology, 6, 388-397.

Cohen, J. (1988). Statistical power analysis for the behavioural science (2nd ed.). Hillsdale, NJ: Lawrence Erlbaum Associates.

Cohen, J. (1992). A power primer. Psychological Bulletin, 112, 155-159.

Cole, T. J., Belizzi, M. C., Flegal, K. M., \& Dietz, W. H. (2000). Establishing a standard definition for child overweight and obesity worldwide: International survey. BMJ, 320, 1240-1243.

Coppens, E., Bardid, F., Deconinck, F. J. A., Haerens, L., Stodden, D., D'Hondt, E., \& Lenoir, M. (2019). Developmental change in motor competence: A latent growth curve analysis. Frontiers in Physiology, 10, 1273.

De Meester, A., Stodden, D., Brian, A., True, L., Cardon, G., Tallir, I., \& Haerens, L. (2016). Associations among elementary school children's actual motor competence, 
perceived motor competence, physical activity and BMI: A cross-sectional study. PLOS ONE, 11, e0164600.

D’Hondt, E., Deforche, B., De Bourdeaudhuij, I., \& Lenoir, M. (2009). Relationship between motor skill and body mass index in 5- to 10-year-old children. Adapted Physical Activity Quarterly, 26, 21-37.

D’Hondt, E., Deforche, B., Gentier, I., De Bourdeaudhuij, I., Vaeyens, R., Philippaerts, R., \& Lenoir, M. (2013). A longitudinal analysis of gross motor coordination in overweight and obese children versus normal-weight peers. International Journal of Obesity, 37, 61-67.

D’Hondt, E., Deforche, B., Gentier, I., Verstuyf, J., Vaeyens, R., Bourdeaudhuij, I., ... Lenoir M. (2014). A longitudinal study of gross motor coordination and weight status in children. Obesity, 22, 1505-1511.

D’Hondt, E., Deforche, B., Vaeyens, R., Vandorpe, B., Vandendriessche, J., Pion, J., ... Lenoir, M. (2010). Gross motor coordination in relation to weight status and age in 5- to 12-year-old boys and girls: A cross-sectional study. International Journal of Pediatric Obesity, 6, e556-e564.

Gentier, I., D’Hondt, E., Shultz, S., Deforche, B., Augustijn, M., Hoorne, S., ... Lenoir, M. (2013). Fine and gross motor skills differ between healthy-weight and obese children. Research in Developmental Disabilities, 34, 4043-4051.

Graf, C., Koch, B., Kretschmann-Kandel, E., Falkowski, G., Christ, H., Coburger, S., ... Dordel, S. (2004). Correlation between BMI, leisure habits and motor abilities in childhood (CHILT-Project). International Journal of Obesity, 28 , 22-26.

Henriksson, P., Cadenas-Sanchez, C., Leppänen, M. H., Delisle Nyström, C., Ortega, F. B., Pomeroy J., ... Löf, M. (2016). Associations of fat mass and fat-free mass with physical fitness in 4-year-old children: Results from the MINISTOP Trial. Nutrients, 8, E473.

Henrique, R. S., Bustamante, A. V., Freitas, D. L., Tani, G., Katzmarzyk, P. T., \& Maia, J. A. (2017). Tracking of gross motor coordination in Portuguese children. Journal of Sports Sciences, 36, 220-228.

Herman, K. M., Craig, C. L., Gauvin, L., \& Katzmarzyk, P. T. (2009). Tracking of obesity and physical activity from childhood to adulthood: The Physical Activity Longitudinal Study. International Journal of Pediatric Obesity, 4, 281-288.

Katzmarzyk, P. T., Janssen, I., \& Ardern, C. I. (2003). Physical inactivity, excess adiposity and premature mortality. Obesity Reviews, 4, 257-290.

Kiphard, E. J., \& Schilling, F. (1974). KörperkoordinationTest-für-Kinder (Manual) [Gross motor coordination test for children]. Weinheim, Germany: Beltz Test.

Kiphard, E. J., \& Schilling, F. (2007). KörperkoordinationTest-für-Kinder (Manual) [Gross motor coordination test for children] (2nd ed.). Göttingen, Germany: Beltz Test.
Lobstein, T., Baur, L., \& Uauy, R. (2004). Obesity in children and young people: A crisis in public health. Obesity Reviews, 5, 4-85.

Lopes, V. P., Malina, R. M., Maia, J. A. R., \& Rodrigues, L. P. (2018). Body mass index and motor coordination: Nonlinear relationships in children 6-10 years. Child: Care, Health and Development, 44, 443-451.

Lopes, V. P., Stodden, D. F., Bianchi, M. M., Maia, J. A., \& Rodrigues, L. P. (2012). Correlation between BMI and motor coordination in children. Journal of Science and Medicine in Sport, 15, 38-43.

Lopes, V. P., Stodden, D. F., \& Rodrigues, L. P. (2017). Effectiveness of physical education to promote motor competence in primary school children. Physical Education and Sport Pedagogy, 22, 589-602.

Lubans, D. R., Morgan, P. J., Cliff, D. P., Barnett, L. M., \& Okely, A. D. (2010). Fundamental movement skills in children and adolescents - Review of associated health benefits. Sports Medicine, 40, 1019-1035.

Malina, R. M., Bouchard, C., \& Bar-Or, O. (2004). Growth, maturation and physical activity. Champaign, IL: Human Kinetics.

Ng, M., Fleming, T., Robinson, M., Thomson, B., Graetz, N., Margono, C., ... Gakidou, E. (2014). Global, regional, and national prevalence of overweight and obesity in children and adults during 1980-2013: A systematic analysis for the Global Burden of Disease Study 2013. Lancet, 384, 766-781.

Okely, A. D., Booth, M. L., \& Chey, T. (2004). Relationship between body composition and fundamental movement skills among children and adolescents. Research Quarterly for Exercise and Sport, 75, 238-247.

Robinson, L. E., Stodden, D. F., Barnett, L. M., Lopes, V. P., Logan, S. W., Rodrigues, L. P., \& D’Hondt, E. (2015). Motor competence and its effect on positive developmental trajectories of health. Sports Medicine, 45, 1273-1284.

Ružbarská, I. (2016). Physical fitness of primary school children in the reflection of different levels of gross motor coordination. Acta Gymnica, 46, 184-192.

Stodden, D. F., Goodway, J. D., Langendorfer, S. J., Roberton, M. A., Rudisill, M. E., Garcia, C., \& Garcia, L. E. (2008). A developmental perspective on the role of motor skill competence in physical activity: An emergent relationship. Quest, 60, 290-306.

Wang, Y., \& Lobstein, T. (2006). Worldwide trends in childhood overweight and obesity. International Journal of Pediatric Obesity, 1, 11-25.

Wrotniak, B. H., Epstein, L. H., Dorn, J. M., Jones, K. E., \& Kondilis, V. A. (2006). The relationship between motor proficiency and physical activity in children. Pediatrics, 118, e1758-e1765. 